\title{
$\underline{\text { June } 1927} \quad \underline{\text { Vol. XLII., No. } 6}$ \\ The Journal of \\ Laryngology and Otology

\author{
EDITÉD BY \\ A. LOGAN TURNER AND J. S. FRASER
} \\ Contents
}

Have we a Resonance Theory of Hearing or only a Resonance Hypothesis.

- George WiLKinson

Endocrine Hypofunction in Ear Disease. . Dana W. Drury

An Efficient Insulating Material * . F. H. B. Norrie

Clinical ReCORD-

Cardiospasm . . . . . J. Bowring Horgan

Societies' Proceedings :-

Royal Society of Medicine-Section of Laryngology.

Society of German LaRyngo-Otologists-(continued).

ABstracts :-

THE EAR

The Nose and Accessory Sinuses

Models of the Labyrinth .

iA. H. Ceeatle

ReVIEWS OF BooKs.

V. E. Negus

OBITUARY :-

Louis Hemington Pegler, M.D.(Edin.), M.R.C.S. (Eng.) . . . . IRWIN MOORE

General Notes.

\section{Edinburgh: Oliver and Boyd London : 33 Paternoster Row}




\section{The Journal of \\ Laryngology and Otology}

(Founded in 1887 by MORELI MACKENZIE and NORRIS WOLFENDEN) EDITED BY

A. LOGAN TURNER AND J. S. FRASER ASSISTED BY

DOUGLAS GUTHRIE AND IRWIN MOORE

1. Original Articles are accepted on the condition that they have not been published elsewhere.

2. Manuscripts should be typewritten, on one side only of the paper, and well spaced.

3. Galley proofs and engraver's proofs of illustrations are sent to the author. Corrections, which should be kept to a minimum, must be clearly marked and no additional matter should be added.

4. The order for reprints should be sent when returning galley proofs, and for this purpose special forms are supplied, on which the price of the reprints is stated.

5. Authors of Original Communications on Oto-Laryngology in other Journals are invited to send a copy, or two reprints, to the Journal of Laryngology. If they are willing, at the same time, to submit their own abstract (in English, French, Italian, or German) it will be welcomed.

6. Editorial Communications should be addressed to "EDITORS, Journal of Laryngology, c/o Messrs OLIVER AND BOYD, Tweeddale Court, Edinburgh."

7. The Annual Subscription is Forty Shillings, post free, and is payable in advance.

8. Single copies of back numbers, both of the present and the previous series, are on sale at Four Shillings each.

9. An Annual Subscription can be commenced with any number of the Journal, and the preceding numbers of the current year can be purchased at Four Shillings each.

\section{UNITED STATES OF AMERICA}

Orders for this Journal, for single parts or yearly subscriptions, can be sent either through a local bookseller, or to Messrs G. E. STECHERT \& Co., 31-33 East 1oth Street, New York.

\section{EAR - M ICROSCOPE \\ accordlag to E. Lüscher \\ magnifylog $10-50$ fold}

Described in the "Zeitschrift für Hals-Nasen und Ohrenheilkunde." Vol. 17, I927, page 403.

Haag-Streit, Berne

Manufacturer of

Optical - Medical - Instruments

\section{Please ask for detailed Prospectus}




\section{Why the Hanovia}

\section{Kromayer Quartz Lamp \\ is Unique}

Firstly, it has the distinction of being the introducer of Quartz Light Therapy to the Medical Profession in I906. The new water-cooled models are wonderful products of mechanical skill. Every ounce of superfluous weight has been eliminated. They combine extreme flexibility with beauty of design found in no other equipment.

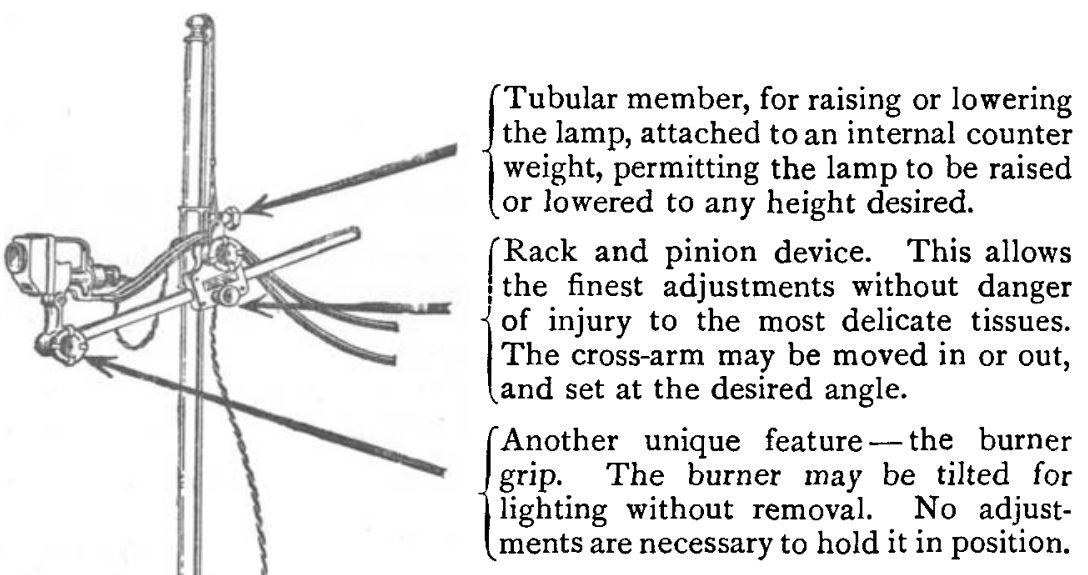

The Hanovia KROMAYER Lamp has the entire quartz mercury anode type of burner, for which it is justly famed, and is strengthened considerably by the redesigning of the burner casing, a step which has increased the latitude and made it extremely light.

For Literature on its use in Oto-laryngology, Dermatology, Gynæcology, etc.

For Direct Current $\quad \$ 37$ I4 For Alternating Current $£ 51$ IO 0 $\left(E x^{*}\right.$ Works, Slough)

Request Set 18

\section{THE BRITISH HANOVIA QUARTZ LAMP CO. LTD. SLOUGH BUCKS}

London Showroom: 3 Victoria Street, Westminster, S.W.I. Telephone: Franklin 6242 


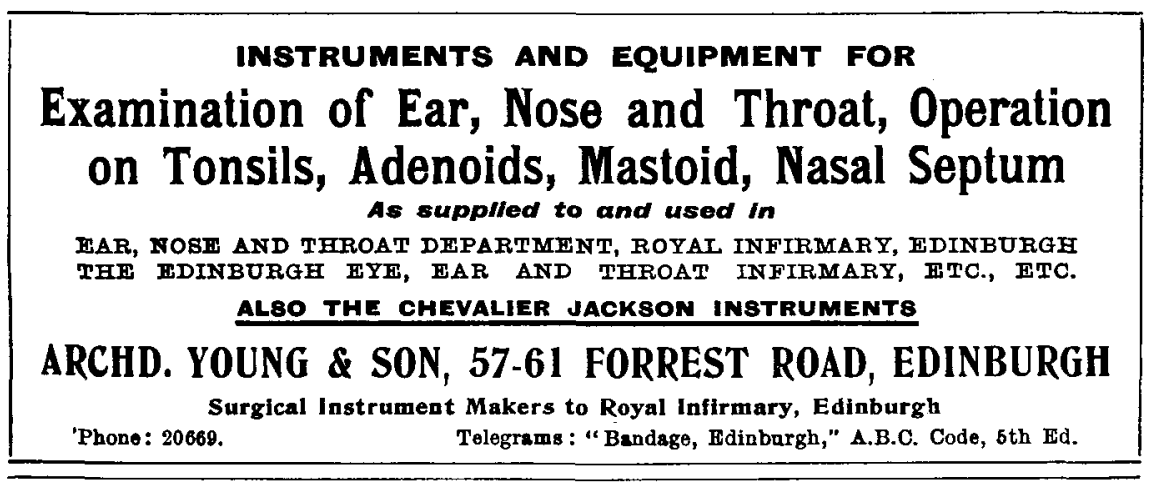

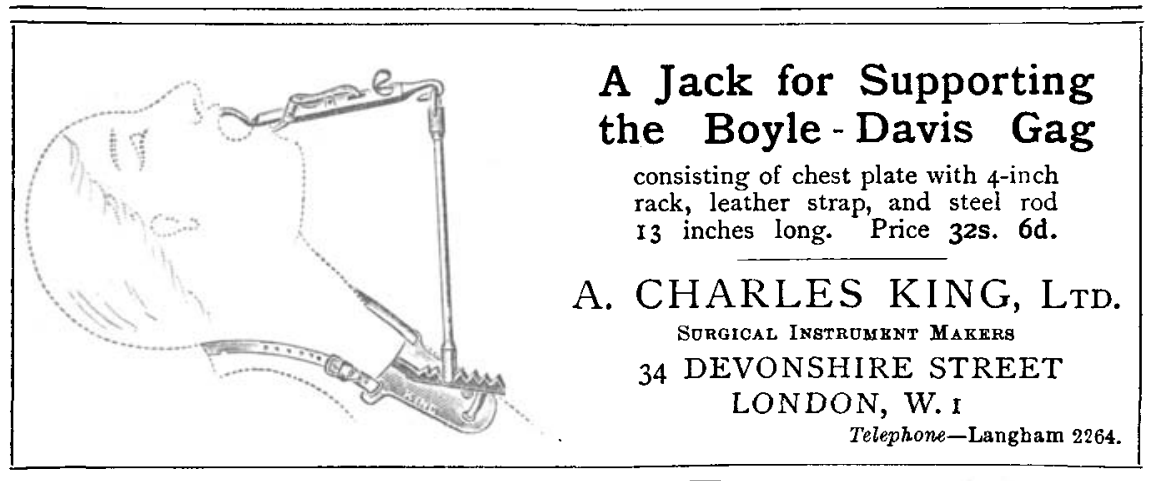

\section{ORAR GOL}

(A.F.D.)

An electrically prepared suspension of colloidal silver and gold for

\section{RH INO = LARYNGOLOGY OPHTHALMOLOGY AND GENERAL ANTISEPSIS.}

Indicated in the same diseases as colloidal silver, Orargol has a superior action because of the addition of the powerfully anti-infectious colloidal gold.

\section{LITERATURE and SAMPLES}

FROM

THE ANGLO-FRENCH DRUG Co. Ltd., 238a GRAY'S INN ROAD, LONDON :: W.C.I.

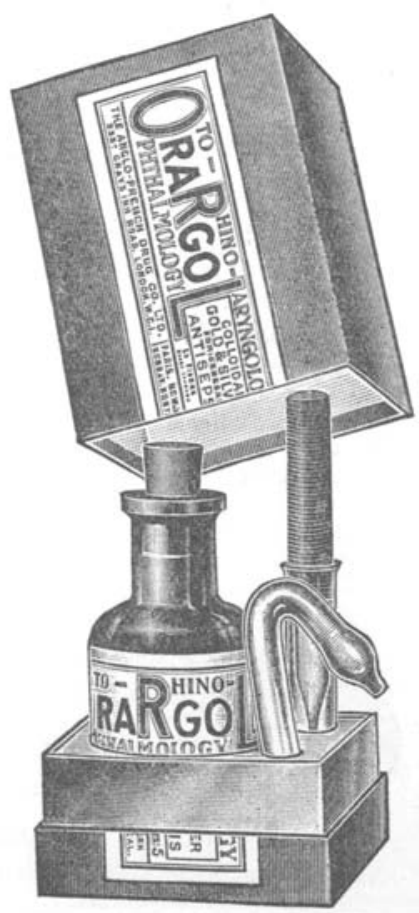




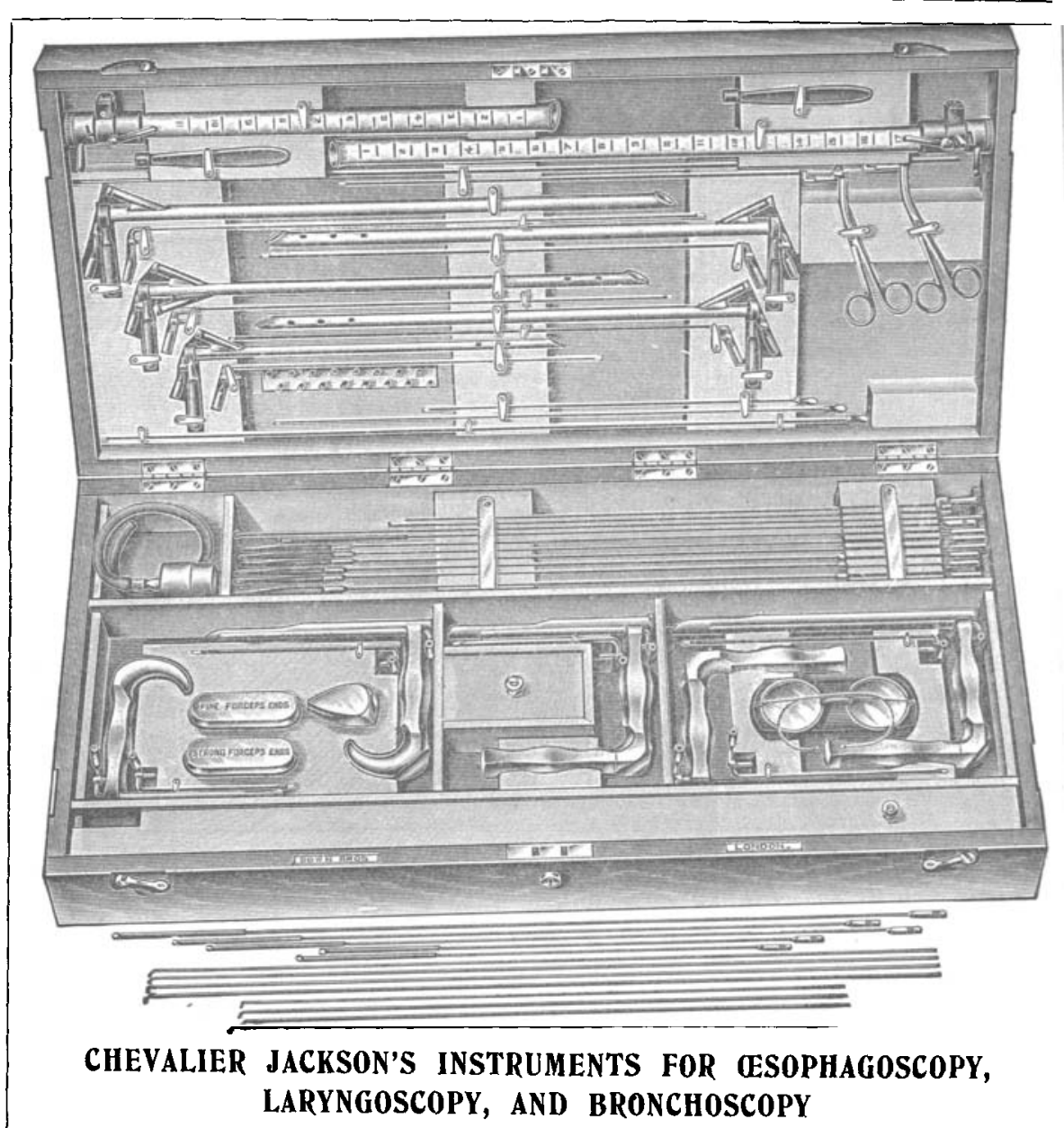

New Models as made for Walter G. Howarth, F.R.C.S.

Each Instrument is made in accordance with the details of Chevalier Jackson's most recent models, and each is supplied with a spare light carrier, i.e., 2 light carriers and 2 lamps. All the models have been redesigned with a view to rendering them more easily cleansed; all the crevices and corners for the dirt have been taken away.

To ensure better visibility the tips of the forceps are black.

The Howarth-Jackson's Instruments are less expensive than other American or English models, and a further economy has been effected by rendering the instrument tips interchangeable, thus reducing the number of forceps handles and tips required.

The lamps are 2.5 volt and more durable than the usual models.

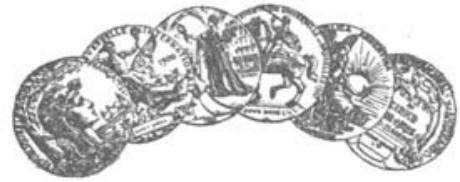

Telegrams-" DOWN, LONDON." Telephone-HOP 4400 ( 4 Ines).
Manufactured only by DOWN BROS., L?.

SURGICAL INSTRUMENT MAKERS

21 and 23 ST THOMAS'S STREET

LONDON, S.E. 1

(Opposite Guy's Hosplta] 


\title{
DeVILBISS SPRAY No. 15
}

FULLY

GUARANTEED

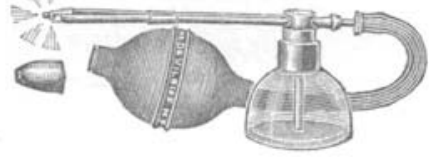

FOR ALL

PURPOSES

For Spraying the Nose and Throat with Olls and Aqueous Solutions

\section{Important}

The adjustable tip permits spraying in any direction, and is especially important when the bronchial tubes or the post-nasal cavities are to be treated.

When prescribing, please specify

\author{
"DeVilbiss Spray No. 15" \\ (of all Chemists and Surgical Instrument makers)
}

Complete illustrated Catalogue from

DeVILBISS, CO., LTD., WEST DRAYTON, MIDDLESEX

\section{CENTRAL LONDON THROAT, NOSE, AND EAR HOSPITAL

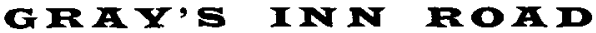 \\ (Near King's Cross Stations)}

DAILY CLINICS. LECTURES ON FRIDAYS, 4 p.m.

OVER 11,000 NEW PATIENTS LAST YEAR. 50,000 ATTENDANCES.

IN-PATIENT DEPARTMENT, 43 BEDS. In-Patient Operations Daily.

SPECIAL INTENSIVE COURSE OF LECTURES AND DEMONSTRATIONS

(including Operative Surgery Course and Peroral Endoscopy Class), in

co-operation with the Fellowship of Medicine, twice yearly - May co-operation

COURSE IN METHODS OF EXAMINATION \& DIAGNOSIS at frequent intervals.

\begin{tabular}{|c|c|}
\hline \multicolumn{2}{|c|}{ SURGEON8 } \\
\hline Dr ANDREW WyLIE & Mr Nicol RaNKIN \\
\hline Dr DAN MCKENZIE & Mr ARCHER RYLAND \\
\hline Mr HAROLD KISCH & Mr F. W. WATKYN-THOMAS \\
\hline 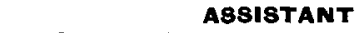 & $\mathbf{N S}$ \\
\hline . GILL-CARE & MOUR BROWN \\
\hline
\end{tabular}

Mr J. D. MCLagGAN

CLINICAL ABSISTANTS

Are appointed from among those duly qualified gentlemen who have been enrolled as Post-Graduate Students of the Hospital.

\section{FEES}

For attendance on the practice of the Hospital-

Three months . . . 5 guineas | Six months . . . . 8 guineas

Special Course, 18 guineas, i.e.-

Clinical Course, $£ 5$, 5s., Operative Surgery, $67,7 \mathrm{~s}$., Endoscopy, $66,6 \mathrm{~s}$. Further particulars on application to 


\title{
CONTENTS
}

Have we a Resonance Theory of Hearing or only a Resonance HypotHesis? George Wilkinson, F.R.C.S. (Sheffield) . . . 365

Endocrine Hypofunction in Ear Disease. Dana W. Drury, M.D., Boston, Mass. . $\quad . \quad$. $\quad$.

An Efficient Insulating Material. F. H. B. Norrie, M.B., F.R.C.S.E., Calcutta.

Clinical ReCORD-

Cardiospasm. J. Bowring Horgan, M.B., Ch.B., D.L.O., Cork . $\quad 388$

Societies' Proceedings-

Royal Society of Medicine-Section of Laryngology . . . . 390

Society of German Laryngo-Otologists-(continued) . . . 402

ABSTRACTS-

The Ear

The Nose and Accessory Sinuses

Models of the Labyrinth. A. H. Cheatle, C.B.E., F.R.C.S., and

V. E. Negus, M.S., F.R.C.S. • . . . . . $\quad 4423$

REviews OF Books . . . . . . . . . . . 424

Obituary : Louis Hemington Pegler, M.D.(Edin.), M.R.C.S.(Eng.). Irwin

Moore . . . . . . . . . . . . . 427

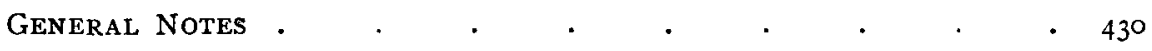

\section{HOSPITAL FOR DISEASES OF THE THROAT}

GOLDEN SQUARE, LONDON, W. 1

\author{
HONORARY MEDICAL STAFF

\begin{tabular}{ll}
\multicolumn{2}{c}{ Surgeons } \\
Mr T. JEFFERSON FAULDER & Mr G. A. DAwSON \\
Mr GEORGE W. BADGEROW & Mr GILBERT CHUBB \\
Mr LIONEL COLLEDGE & Mr THEODORE JUST
\end{tabular}

\begin{tabular}{ll}
\multicolumn{3}{c}{ Assistant Surgeons } \\
$\mathrm{Mr}$ ORMEROD & $\mathrm{Mr}$ DINGLEY \\
$\mathrm{Mr}$ BEDFORD RUSSEL & Mr SANDIFORD
\end{tabular}

The Hospital, which has for some considerable time been undergoing very extensive reconstruction and extension, has nearly 80 beds for In-patients and an annual Out-patient attendance of over 60,000 .

\section{CLINICAL INSTRUCTION}

Clinical Instruction in the Diagnosis and Treatment of Diseases of the Ear, Nose and Throat is daily given in the Out-patient Department from 2 to $5 \mathrm{p} . \mathrm{m}$. On Tuesdays and Fridays from 6.30 to 9 p.m. also. Major operations are performed daily, except Mondays and Saturdays, in the In-patient Operating Theatres. Minor operations are performed in the Out-patient Department by the Assistant Surgeons on four mornings a week.

Practitioners and Medical Students are admitted to the practice of the hospital and Clinical Assistants, whose duty it is to assist the staff, are appointed from time to time among them. For further information apply to the Dean, THEODORE JUST. 